\title{
Vaccines to combat river blindness: expression, selection and formulation of vaccines against infection with Onchocerca volvulus in a mouse model.
}

\author{
Jessica A. Hess \\ Thomas Jefferson University \\ Bin Zhan \\ Baylor College of Medicine \\ Sandra Bonne-Annee \\ Thomas Jefferson University \\ Follow this and additional works at: https://jdc.jefferson.edu/mifp \\ Iossica M. Deckman

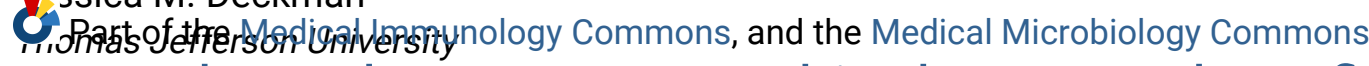 \\ het us know, how access to this document benefits you
}

Baylor College of Medicine

\section{Recommended Citation}

Hess, Jessica A.; Zhan, Bin; Bonne-Annee, Sandra; Deckman, Jessica M.; Bottazzi, Maria Elena; Hotez, Peter J.; Klei, Thomas R R.; Lustigman, Sara; and Abraham, David, "Vaccines to combat river blindness: expression, selection and formulation of vaccines against infection with Onchocerca volvulus in a mouse model." (2014). Department of Microbiology and Immunology Faculty Papers. Paper 145.

https://jdc.jefferson.edu/mifp/145

This Article is brought to you for free and open access by the Jefferson Digital Commons. The Jefferson Digital Commons is a service of Thomas Jefferson University's Center for Teaching and Learning (CTL). The Commons is a showcase for Jefferson books and journals, peer-reviewed scholarly publications, unique historical collections from the University archives, and teaching tools. The Jefferson Digital Commons allows researchers and interested readers anywhere in the world to learn about and keep up to date with Jefferson scholarship. This article has been accepted for inclusion in Department of Microbiology and Immunology Faculty Papers by an authorized administrator of the Jefferson Digital Commons. For more information, please contact: JeffersonDigitalCommons@jefferson.edu. 


\section{Authors}

Jessica A. Hess, Bin Zhan, Sandra Bonne-Annee, Jessica M. Deckman, Maria Elena Bottazzi, Peter J. Hotez, Thomas R R. Klei, Sara Lustigman, and David Abraham 


\title{
Vaccines to combat river blindness: expression, selection and formulation of vaccines against infection with Onchocerca volvulus in a mouse model
}

\author{
Jessica A. Hess ${ }^{a}$, Bin Zhan ${ }^{b, c}$, Sandra Bonne-Année ${ }^{a}$, Jessica M. Deckman ${ }^{a}$, Maria Elena \\ Bottazzi $^{\mathrm{b}, \mathrm{c}}$, Peter J. Hotez ${ }^{\mathrm{b}, \mathrm{c}}$, Thomas R. Klei ${ }^{\mathrm{d}}$, Sara Lustigman ${ }^{\mathrm{e}}$, and David Abraham ${ }^{\mathrm{a},{ }^{*}}$ \\ aDepartment of Microbiology and Immunology, Jefferson Medical College, Thomas Jefferson \\ University, 233 S. 10th Street, Philadelphia, PA 19107, USA \\ bDepartment of Pediatrics, National School of Tropical Medicine, Baylor College of Medicine, \\ Houston, TX 77030, USA \\ 'Sabin Vaccine Institute and Texas Children's Hospital Center for Vaccine Development, 1102 \\ Bates St, Ste. 550, Houston, TX 77030, USA \\ ${ }^{\mathrm{d} D e p a r t m e n t}$ of Pathobiological Sciences, LSU School of Veterinary Medicine, Louisiana State \\ University, 1909 Skip Bertman Drive, Baton Rouge, LA, 70803 USA \\ eLaboratory of Molecular Parasitology, Lindsley F. Kimball Research Institute, New York Blood \\ Center, 310 E 67th St, New York, NY 10065, USA
}

\section{Abstract}

Human onchocerciasis is a neglected tropical disease caused by Onchocerca volvulus and an important cause of blindness and chronic disability in the developing world. Although mass drug administration of ivermectin has had a profound effect on control of the disease, additional tools are critically needed including the need for a vaccine against onchocerciasis. The objectives of the present study were to: (i) select antigens with known vaccine pedigrees as components of a vaccine; (ii) produce the selected vaccine antigens under controlled conditions, using two expression systems and in one laboratory and (iii) evaluate their vaccine efficacy using a single immunization protocol in mice. In addition, we tested the hypothesis that joining protective antigens as a fusion protein or in combination, into a multivalent vaccine, would improve the ability of the vaccine to induce protective immunity. Out of eight vaccine candidates tested in this study, $O v-103, O v$-RAL-2 and $O v$-CPI-2M were shown to reproducibly induce protective immunity when administered individually, as fusion proteins or in combination. Although there was no increase in the level of protective immunity induced by combining the antigens into one vaccine, these antigens remain strong candidates for inclusion in a vaccine to control onchocerciasis in humans.

(C) 2014 Australian Society for Parasitology. Published by Elsevier Ltd. All rights reserved. *Corresponding author. Tel.: +1 215-503-8917; fax: +1 215-923-9248. david.abraham@jefferson.edu. Publisher's Disclaimer: This is a PDF file of an unedited manuscript that has been accepted for publication. As a service to our customers we are providing this early version of the manuscript. The manuscript will undergo copyediting, typesetting, and review of the resulting proof before it is published in its final citable form. Please note that during the production process errors may be discovered which could affect the content, and all legal disclaimers that apply to the journal pertain. 


\section{Keywords}

Onchocerca volvulus; Vaccine; Mice; Multivalent vaccine

\section{Introduction}

Human onchocerciasis is a neglected tropical disease caused by Onchocerca volvulus and an important cause of blindness, skin disease and chronic disability in the developing world. Through mass drug administration of ivermectin, onchocerciasis has been recognized as a potential candidate for control of morbidity (blindness and skin pathology) and for global elimination by focusing on interruption of transmission (http://www.emro.who.int/ neglected-tropical-diseases/ntd-infocus/ntd-roadmap.html, 2014). In some foci of the Americas, Mali, Senegal and Nigeria (Kaduna), there has been encouraging evidence that the elimination of onchocerciasis may be possible with mass drug administration of ivermectin, when high levels of therapeutic and geographic coverage over many years have been achieved (Diawara et al., 2009). However, numerous and formidable technical and logistical obstacles must still be overcome before the ambitious goal of elimination can be attained in Africa. These include: (i) the practical complication of treating people for 14 - 35 years compounds the difficulty of implementing this plan (Winnen et al., 2002; Boatin and Richards, 2006); (ii) experimental studies indicate that susceptibility to reinfection may increase after treatment, further complicating the disruption of the transmission cycle (Duke and Moore, 1968; Abraham et al., 2002; Njongmeta et al., 2004); (iii) recent reports demonstrate that $O$. volvulus in some communities in Africa may have developed resistance to ivermectin (Huang and Prichard, 1999; Kohler, 2001; Awadzi et al., 2004a, b; Ardelli et al., 2005; Bourguinat et al., 2005, 2007; Eng and Prichard, 2005; Osei-Atweneboana et al., 2007); and finally (iv) use of mass drug administration is already compromised in large areas of central Africa where loiasis is co-endemic. Ivermectin cannot be used for the treatment of individuals with high Loa loa microfilaremia due to the risk of developing severe adverse reactions including an encephalopathy (Gardon et al., 1997). Therefore, additional tools are critically needed and include the need for a vaccine against onchocerciasis to complement the present control measures and thus potentially eliminate this infection from humans.

Protective immunity against $O$. volvulus larvae has been demonstrated in cattle (Tchakoute et al., 2006), mice (Lange et al., 1993) and immuno-epidemiological studies strongly support the hypothesis that protective immunity against onchocerciasis exists in humans (MacDonald et al., 2002), thereby proving the conceptual underpinnings that a vaccine can be produced against this infection. The $O$. volvulus vaccine would be indicated as a product to protect vulnerable populations living in endemic areas against infection and disease. Reduction in adult worm burden would potentially reduce the number of microfilariae produced by the adult female worms and thus pathology and potentially also the rates of transmission within these endemic regions.

A mouse model was developed for studying immunity to the larval stages of $O$. volvulus in which larvae are implanted in mice within diffusion chambers (Lange et al., 1993).

Protective immunity was demonstrated in this model following immunization with irradiated 
infective L3s (Lange et al., 1993; Abraham et al., 2001, 2004). To develop a vaccine with potential clinical application, the model was selected as a moderate throughput means to test recombinant protein or larval vaccines. Recombinant $O$. volvulus antigens, selected using a variety of criteria, were shown previously to exhibit varying degrees of promise as possible vaccine candidates. In a previously published study, 15 recombinant $O$. volvulus antigens out of the 44 screened using the $O$. volvulus-mouse model were found to be protective (Lustigman et al., 2002). Based on the following selection criteria, seven of these protective antigens were selected for further evaluation in the current study: (i) being nematode- or parasite-specific with or without known function. High sequence homology between parasite and mammalian proteins has the potential risk of inducing autoimmunity; (ii) localization of the corresponding native proteins in larvae by immunoelectron microscopy in one or more regions that are also recognized by antibodies from humans and/or mice with protective immunity to $O$. volvulus (Lustigman et al., 2003); (iii) being recognized by antibodies from humans with protective immunity or cattle, chimpanzees, mice immunized with irradiated larvae; (iv) the ability of antibodies targeting the parasite antigen to kill larvae in vitro; (v) having homologues that have been shown to also induce protection in other filarial or nematode host-parasite systems (Table 1). In addition, CPI-2 was altered by site-directed mutagenesis to disrupt the asparaginyl endopeptidase inhibitory activity to produced $\mathrm{Ov}$ CPI-2M (Gregory and Maizels, 2008). It has been demonstrated in the Litomosoides sigmodontis/mouse system that this alteration of the antigen enhanced the antigen-specific immune response (Babayan et al., 2012).

The objective of the present study was to produce all candidate vaccine antigens under controlled conditions, using two protein expression systems, Escherichia coli and the yeast Pichia pastoris, and to evaluate their vaccine efficacy using a single harmonized immunization protocol. In addition, we tested the hypothesis that adding protective vaccine candidates together into a multivalent vaccine would improve the ability of the vaccine to induce protective immunity.

\section{Materials and methods}

\subsection{Expression and purification of $O$. volvulus vaccine antigens}

Yeast codon optimized DNAs encoding for selected $O$. volvulus vaccine candidates: $O v$ B20-C (77 amino acids in the C-terminal region of B20 that were shown to be protective), $O v$-RBP-1, $O v$-CPI-2, $O v$-CPI-2M, $O v$-103, $O v$-ALT-1, $O v$-RAL-2 and $O v$-ASP-1, minus the signal peptides at the N-terminus, were synthesized by GenScript (Piscataway, NJ, USA) and subsequently subcloned in-frame into the yeast expression vector pPinka-HC (Life Technologies, Carlsbad, CA, USA) with $\mathrm{XhoI} / \mathrm{KpnI}$ sites and E. coli expression vector pET41a (EMDMillipore, Billercia, MA, USA) with the fusion GST deleted (NdeI/XhoI). The correct open reading frame (ORF) was confirmed by double-stranded sequencing using the vector flanking primers (5'AOX1/CYC1 for pPinka-HC and T7 promoter/T7 terminator for pET41a). For expression in yeast, the recombinant plasmids were linearized with AflII digestion and then transformed by electroporation into PichiaPink strain\#4 with protease A and B knockout ( ep $4 / \mathrm{prbl}^{-}$) to prevent $P$. pastoris -derived protease degradation. Yeast transformants were selected on P. pastoris adenine dropout (PAD) selection plates. The 
expression of recombinant filarial antigens with hexahistidine (6His)-tag at the C-terminus was induced with $0.5 \%$ methanol and the soluble recombinant proteins secreted into the culture were purified with immobilized metal ion affinity chromatography (IMAC) as described previously (Goud et al., 2004). For expression in E. coli, the recombinant constructs cloned into pET41a were transformed into BL21(DE3) (EMDMillipore) and recombinant proteins were induced with $1 \mathrm{mM}$ isopropyl- $\beta$-thiogalactoside (IPTG) and purified with IMAC as previously described (Zhan et al., 2002).

In order to test the synergistic protection of two or three $O$. volvulus protective antigen combinations, the selected three protective $O$. volvulus antigens, $O v-103, O v$-RAL-2 and $O v$-CPI-2M, were fused together as a triple antigen $(O v-103-\mathrm{RAL}-2-\mathrm{CPI} 2 \mathrm{M})$ or as two double antigens $(O v-103-\mathrm{RAL}-2$ and $O v$-RAL-2-CPI2-M) by using a flexible linker (KGPDVPETNQQCPSNTGMTD) obtained from $\mathrm{Na}$-ASP-1 structure between two pathogenesis-related (RP) domains (Asojo et al., 2005). The yeast codon optimized fusion DNAs were subcloned into either yeast expression vector pPICZaA (Life Technologies) or E. coli expression vector pET41a (EMD Millipore) with GST knockout. The recombinant fusion proteins were expressed and purified using the same methods described above except for the use of yeast strain P. pastoris X-33 (Zhan et al., 2002). The purity and the molecular weight of purified recombinant proteins were analyzed by SDS-PAGE using pre-cast 4-20\% Tris-glycine gels (Life Technologies) and stained with Coomassie brilliant blue R-250 (Fisher Scientific, Pittsburg, PA USA).

\subsection{Source of parasites and mice}

Black flies (Simulium damnosum) were fed on consenting donors that were infected with $O$. volvulus Institutional Review Board (IRB) protocol 320 approved by the New York Blood Center, USA and the Kumba, Cameroon IRB). After 7 days the flies were dissected to collect developed L3s, cleaned and cryopreserved in dimethyl sulfoxide and sucrose by using Biocool II computerized freezing equipment (FTS Systems Inc., Stone Ridge, NY, USA) as previously described (Trpis et al., 1993)

Male BALB/cByJ mice were purchased from The Jackson Laboratory (Bar Harbor Maine, USA) at 6-8 weeks of age. Mice were kept in the Laboratory Animal Sciences Facility at Thomas Jefferson University, USA. All mice were housed in micro-isolator boxes in a room that was pathogen-free and under temperature, humidity and light cycle controlled conditions. Mice were fed autoclavable rodent chow and given water ad libitum. All protocols using mice were approved by the Institutional Animal Care and Use Committee of Thomas Jefferson University.

\subsection{Immunization and challenge protocol}

Mice were immunized with $25 \mu \mathrm{g}$ of the produced vaccine antigens in $0.1 \mathrm{ml}$ of Tris Buffered Saline (TBS) formulated with $0.1 \mathrm{ml}$ of 1:5 Rehydragel LV (alum) in PBS (General Chemical, Parsippany, NJ, USA). Mice were immunized s.c. in the nape of the neck, followed by two booster injections 14 and 28 days later. 
Cryopreserved L3s were defrosted slowly in two steps, first $15 \mathrm{~min}$ on dry ice followed by a $37^{\circ} \mathrm{C}$ water bath. Once thawed, the L3s were washed five times in a 1:1 mixture of NCTCand Iscove's modified Dulbecco's medium with $100 \mathrm{U}$ of penicillin, $100 \mu \mathrm{g}$ of streptomycin, $100 \mu \mathrm{g}$ of gentamicin and $30 \mu \mathrm{g}$ of chloramphenicol per ml. Diffusion chambers were constructed from $14 \mathrm{~mm}$ Lucite rings covered with $5.0 \mu \mathrm{M}$ pore-size Durapore membranes (EMDMillipore) and fused together using an adhesive containing a 1:1 mixture of 1,2dichloroethane (Fisher Scientific) and acryloid resin (Rohm and Haas, Philadelphia, PA, USA). The constructed diffusion chambers were then sterilized via $100 \%$ ethylene oxide followed by $12 \mathrm{~h}$ aeration.

Challenge infections occurred 14 days after the final booster with $25 \mathrm{~L} 3 \mathrm{~s}$ delivered within a diffusion chamber. The diffusion chambers were implanted in a s.c. pocket on a rear flank of each mouse. Recovery of the chambers was performed 21 days later and larval survival was determined based on mobility and morphology of the remaining larvae. Protective immunity was calculated in two ways: (i) Percentage of reduction in larvae was calculated as follows: $\%$ reduction $=(($ average worm survival in control mice - average worm survival in immunized mice $) \div$ average worm survival in control mice) $\times 100$. (ii) Host protection was calculated as follows: (number of immunized mice with parasite recovery levels below the lower S.D. of parasite recovery in control mice $\div$ total number of immunized mice) $\times 100$. Host cells within the diffusion chamber were collected and analyzed by centrifugation onto slides using a Cytospin 3 (Shandon Inc, Pittsburgh, PA, USA) and then stained for differential cell counts using Hemastain 3 (Fisher Scientific).

\subsection{ELISA}

Serum was collected at the time of recovery for antigen-specific IgG analysis. Maxisorp 96well plates (Nunc Nalgene International, Rochester, NY, USA) were coated with $2 \mathrm{ug} / \mathrm{ml}$ of the immunizing recombinant antigen in $50 \mathrm{mM}$ Tris-Cl coating buffer, $\mathrm{pH} 8.8$, overnight at $4^{\circ} \mathrm{C}$. Plates were washed with deionized water between each step. Plates were blocked with borate buffer solution (BBS) (0.17 M boric acid, $0.12 \mathrm{M} \mathrm{NaCl}, 0.5 \%$ tween $20,0.025 \%$ BSA, 1 mM EDTA, pH 8.2) at room temperature for $30 \mathrm{~min}$. Individual sera were diluted to an appropriate starting concentration with BBS and serially diluted; plates were sealed and incubated at $4{ }^{\circ} \mathrm{C}$ overnight. Biotinylated IgG (eBioscience, San Diego, CA, USA) was diluted 1:250 in BBS and incubated for $1 \mathrm{~h}$ at room temperature, followed by ExtrAvidin Px (Sigma, St. Louis, MO, USA) which was diluted 1:1000 in BBS and incubated for $30 \mathrm{~min}$ at room temperature. One component ABTS peroxidase substrate (KPL, Gaithersburg, MD, USA) was added and O.D.s were read after $30 \mathrm{~min}$ at $405 \mathrm{~nm}$ in a Bio-Rad iMark Microplate reader (Bio-Rad, Hercules, CA, USA). ELISA data are presented as endpoint titers which were calculated as the serum dilution from experimental animals that had an O.D. reading three times higher than the O.D. recorded for control serum.

\subsection{Statistical analysis}

All experiments consisted of five to six mice per group and experiments were performed at least twice with consistent results between experiments. Data were analyzed by multifactorial analysis of variance ANOVA with post-hoc Fisher's Least Significant 
Difference (LSD) testing in Systat v.11 (Systat Inc., Evanstown, IL, USA). $P<0.5$ was considered statistically significant.

\section{Results}

\subsection{Evaluation of antigens expressed in E. coli or P. pastoris for their ability to induce protective immunity}

Efforts were made to express the seven selected $O$. volvulus antigens and $O v-\mathrm{CPI}-2 \mathrm{M}$ by both $E$. coli and P. pastoris. With the exception of $O v \mathrm{~B} 20-\mathrm{C}$, which could only be expressed by $E$. coli, all of the antigens were expressed by both E. coli and P. pastoris. Of the seven antigens tested, only $O v-103, O v$-RAL-2 and $O v$-CPI-2M induced statistically significant levels of protective immunity in repeated experiments.

\subsection{Expression of Ov-103, Ov-RAL-2 and Ov-CPI-2M or fusion recombinant proteins in $\mathrm{E}$. coli and P. pastoris}

Onchocerca volvulus vaccine candidates were expressed as soluble recombinant proteins in high yield in P. pastoris and E. coli BL21(DE3) after being induced with $0.5 \%$ methanol for $P$. pastoris and $1 \mathrm{mM}$ IPTG for E. coli, and purified with IMAC. Purified recombinant $O v$-103, $O v$-RAL-2 and $O v$-CPI-2M expressed in P. pastoris or in E. coli migrated at the same molecular mass as calculated by the coding sequence (14.5 kDa, 17.9 kDa and 16.0 kDa, respectively) on SDS-PAGE and Coomassie staining (Fig. 1).

The fusion recombinant proteins of two or three antigen combination $(O v-103-\mathrm{RAL} 2, \mathrm{Ov}$ RAL2-CPI2M and $O v$-103-RAL2-CPI2M) were also expressed in $P$. pastoris and $E$. coli expression systems as soluble proteins and the purified recombinant fusions were shown at the correct molecular weight as estimated by sequences on SDS-PAGE (50.6 kDa, $32.5 \mathrm{kDa}$ and $35.2 \mathrm{kDa}$, respectively) (Fig. 2). Some product-derived degradation was observed in the fusion proteins and these degraded bands could be recognized by anti-His antibody (data not shown). All recombinant proteins including fusions were able to bind completely to alum when the ratio of protein and alum was 1:12.8.

\subsection{Immunization with single antigens to induce protective immunity against 0 . volvulus}

3.3.1. Ov-103-BALB/cByJ mice were immunized with $O v-103$ with alum prepared in both $P$. pastoris and E. coli expression systems. Escherichia coli expressed protein induced an $8 \%$ reduction in larval survival and a 50\% level of host protection, whereas mice immunized with the P. pastoris expressed protein had a statistically significant $30 \%$ reduction in parasite survival and a 63\% level of host protection (Fig. 3A). Differential cell counts were performed at the conclusion of the experiments on the diffusion chamber contents. Comparable numbers of total cells $\left(1.4 \times 10^{6} \pm 1.3 \times 10^{6}\right)$, and percentages of lymphocytes $(5 \pm 7 \%)$, neutrophils ( $52 \pm 20 \%)$, macrophages $(37 \pm 15 \%)$ and eosinophils $(12 \pm 14 \%)$ were seen in the control and immunized mice. Parasite-specific antibody titers show equivalent endpoint titers for mice immunized with $P$. pastoris and $E$. coli expressed $O v$-103 when measured against both the P. pastoris and E. coli expressed proteins (Table 2). Correlation analyses were performed between parasite survival and antibody endpoints titers 
and there were no significant relationships between the amount of antibody produced and the survival of the larvae.

3.3.2. Ov-RAL-2-Mice immunized with $E$. coli expressed $O v$-RAL-2 induced a statistically significant $39 \%$ reduction in larval survival and a $64 \%$ level of host protection, whereas mice immunized with the $P$. pastoris expressed protein induced a $24 \%$ reduction in parasite survival and a 55\% level of host protection (Fig. 3B). As with $O v-103$, differential cell counts showed comparable numbers of total cells, lymphocytes, neutrophils, macrophages and eosinophils in the control and immunized mice. Parasite-specific antibody titers show equivalent endpoint titers for both the P. pastoris and E. coli expressed proteins (Table 2). Again, correlations between parasite survival and antibody endpoints titers did not reveal any significant relationship between the amount of antibody produced and parasite survival.

3.3.3. Ov-CPI-2M-Immunization of mice with $O v$-CPI-2M expressed in both $E$. coli and $P$. pastoris induced statistically significant reductions of $30 \%$ in larval survival and $17 \%$ levels of host protection (Fig. 3C). As with the other two antigens, differential cell counts showed comparable numbers of total and specific cells in the control and immunized mice, and parasite-specific antibody titers had equivalent endpoints (Table 2). There were no significant correlations between antibody endpoint titers and parasite survival.

\subsection{Fusion proteins or concurrent immunization with Ov-103, Ov-RAL-2 and Ov-CPI-2M}

Mice were immunized with $O v$-RAL-2/103 fusion protein expressed in $P$. pastoris and $E$. coli. Immunization with $E$. coli expressed protein significantly reduced larval survival by $21 \%$ and provided a $58 \%$ level of host protection, whereas immunization with P. pastoris expressed protein only reduced larval survival by $11 \%$ and provided a $45 \%$ level of host protection (Fig. 4A). Immunization with $O v$-RAL-2/CPI-2M E. coli fusion protein induced protective immunity with parasite reduction at $34 \%$ and a $50 \%$ level of host protection (Fig. 4B). Analysis of the cells within the diffusion chamber contents showed similar numbers of total cells, lymphocytes, neutrophils, macrophages and eosinophils. Parasite-specific antibody titer endpoints were measured against the individual antigens and the fusion protein. Antibody endpoint titers for the two fusion proteins were significantly higher than the antibody responses in these mice to the individual antigens of which the fusion was composed. The antibody response to $O v$-RAL- 2 and $O v$-CPI-2M by mice immunized with these antigens as part of a fusion were equivalent to the responses seen in mice immunized with antigen individually. However, the parasite-specific antibody titer endpoint to $O v-103$ was approximately eight-fold higher in mice immunized with the antigen as part of a fusion compared with immunization with the individual antigen (Table 2). Once again, there were no significant correlations between antibody endpoints and parasite survival.

A fusion protein consisting of $O v-103, O v-\mathrm{RAL}-2$ and $O v-\mathrm{CPI}-2 \mathrm{M}$ was created to determine whether enhanced protective immunity would be achieved with this triple fused antigen. The $O v$-RAL-2/103/CPI-2M E . coli fusion was tested in comparison with concurrent immunization consisting of the three antigens injected simultaneously but at different locations on the mice. Immunization with the three-antigen fusion protein and the concurrent 
immunization resulted in significant levels of protective immunity, with the fusion inducing a $20 \%$ reduction in larval survival and a $45 \%$ level of host protection and the concurrent immunization resulting in a $25 \%$ reduction in parasite survival and a $64 \%$ level of host protection (Fig. 5). Analysis of the cells within the diffusion chamber contents showed similar numbers of total cells, lymphocytes neutrophils, macrophages and eosinophils. Antibody titer endpoints were measured against the individual antigens and the fusion protein. Mice immunized with the three antigens concurrently had antibody endpoint titers to the three antigens that were comparable with those seen in mice immunized with the three individual antigens (Table 2). Mice immunized with the three-antigen fusion protein had endpoint titers to the single antigens that were comparable with the titers seen in mice immunized with individual antigens. Antibody endpoint titers for the three-antigen fusion protein were significantly higher than the antibody responses in these mice to the individual antigens of which the fusion was composed (Table 2). There were no significant correlations between antibody endpoints and parasite survival.

\section{Discussion}

Previous studies have identified several antigens with either proven or potential efficacy in a vaccine against infection with $O$. volvulus. One of the challenges in comparing these studies is the range of approaches used to produce the recombinant antigens, which were performed by laboratories across the USA and Europe, and the immunization protocols used to test these antigens (Lustigman et al., 2002). The objective of the present study was to produce the eight tested vaccine antigens under controlled conditions, using two expression systems and in one laboratory, and to evaluate their vaccine efficacy using a single immunization protocol. In addition, we tested the hypothesis that joining protective antigens as a fusion protein or in combination into a multivalent vaccine would improve the ability of the vaccine to induce protective immunity.

Out of the eight antigens tested, only $O v-103, O v$-RAL-2 and $O v$-CPI-2M were able to repeatedly induce protective immunity under the experimental conditions used in the present study. There are numerous possible explanations for why the other vaccine antigens did not induce protective immunity as was previously reported, including the immunization regimen, adjuvant formulation, expression system and type of challenge infection. All of the tested antigens evoked significant antibody responses, which suggests that the immunization regimen was adequate. There may have been inadequate activation of other elements of the immune response that collaborate with antibody to kill the parasites.

Previous studies on the role of adjuvants in development of recombinant-antigen vaccines against $O$. volvulus have demonstrated that either alum (Abraham et al., 2001) or FCA was required (McCarthy et al., 2002) or that either adjuvant was successful at enhancing the capability of the antigen to induce protective immunity to the parasite (MacDonald et al., 2004). Immunity to $O$. volvulus induced by irradiated larvae is dependent on Th2 responses (Lange et al., 1994; Abraham et al., 2004) and alum has the recognized ability to stimulate humoral immunity and strong Th2 responses (Kenney et al., 1989; Brewer et al., 1996; Yip et al., 1999). In addition, alum remains one of the few adjuvants that is commonly used in human vaccines, whereas FCA is not recommended for use in humans. Alum was therefore 
selected for use in this study due to its predilection for inducing Th2 responses and due to its acknowledged safety in humans.

Two different expression systems were used in this study. Escherichia coli was selected as it was the original system in which the antigens were produced. Pichia pastoris was used as it provides an expression system in which there are post-translational modifications such as glycosylation that will potentially yield antigens more closely resembling the native proteins (Hohenblum et al., 2004). Seven of the eight tested $O$. volvulus antigens were successfully produced in both expression systems with $O v$-B20-C only produced in E. coli. The finding that some antigens are preferentially expressed in one system over the other has been observed with other antigens (Zhang et al., 2006). Interestingly, all eight antigens, regardless of the expression system, induced robust antibody responses. The three antigens that induced protective immunity had equivalent antibody endpoint titers regardless of the expression system and there was comparable recognition of the antigens from the two expression systems regardless of the source of the immunizing antigen. Yet, mice immunized with $P$. pastoris expressed $O v-103$ had a statistically significant reduction in parasite survival but not with $E$. coli expressed antigen; $O v$-RAL-2 induced a statistically significant reduction in parasite survival only if produced by $E$. coli; and $O v-\mathrm{CPI}-2 \mathrm{M}$ produced in either Pichia or E. coli induced protective immunity. In other studies, no differences were observed in the immune responses induced by E. coli and Pichia expressed antigens (Giersing et al., 2005), whereas some antigens were more immunogenic if produced in E. coli compared with Pichia (Kastenmuller et al., 2013) and yet other antigens were more antigenic if produced in Pichia compared with E. coli (Yang et al., 2012).

Two metrics were used to measure the development of protective immunity. "Larval survival" assessed the number of larvae that were killed in immunized compared with control mice and describes the level of protective immunity within individual mice. "Host protection" measured the percentage of mice that developed significant resistance to the infection and reflects the level of protective immunity within the host population. Immunization with the three protective antigens resulted in equivalent levels of protective immunity based on both metrics. Efforts to resolve why an antigen expressed in one system induced protective immunity, whereas expression in the other system did not induce protective immunity, were not informative. There were no correlations between antigenspecific antibody levels and the number of larvae killed in a mouse. The number and types of cells that migrated into the parasite microenvironment did not vary between control and immunized animals nor between immunized mice that developed protective immunity and immunized mice that did not develop protective immunity. Further analysis of the immune response is required to resolve the molecular mechanism of parasite killing induced by the recombinant antigens. Antibody class and subclass responses, as well as the binding affinity of the antigen-specific antibodies, may govern the potency of the antibodies. Cell analysis needs to be expanded to observe the cells in the parasite microenvironment at the time prior to parasite killing and at the time of larval death. Furthermore, it has been shown that the effector cell eosinophils (Lee et al., 2010), macrophages (Bonne-Annee et al., 2013) and neutrophils (Tsuda et al., 2004; Christoffersson et al., 2012) undergo specific forms of activation dependent on the host or pathogen factors to which those are exposed. It is 
possible that effector cells are recruited to the parasite microenvironment, but are ineffectual due to their activation status. It is hypothesized that in mice with protective immunity, cells are recruited to the parasite and specifically activated into a state in which they can participate with antibody in the killing process.

Multivalent vaccines have been successfully developed against the filarial worm Brugia malayi (Anand et al., 2011; Joseph and Ramaswamy, 2013; Shrivastava et al., 2013) and immunization of calves with a multivalent vaccine against Onchocerca ochengi reduced the development of patency as determined by a decrease in the number of animals with microfilariae in the skin (Makepeace et al., 2009). It was hypothesized that immunizing mice against $O$. volvulus with two or three of the protective antigens would induce elevated levels of protective immunity. Concurrent immunization of mice with all three protective antigens did not induce increased levels of protective immunity compared with immunization with the individual antigens. In a previous study utilizing three recombinant O. volvulus antigens, immunization with the three antigens as a cocktail also resulted in levels of protective immunity equivalent to that induced by the component individual antigens (Abraham et al., 2001). Analysis of antibody responses following immunization with the cocktail of three antigens revealed that some of the antibody responses were reduced compared with that seen in mice immunized with individual antigens (Abraham et al., 2001). It was hypothesized that there was competition between the antigens in the cocktail, with some of the antigens dominating the immune response (Abraham et al., 2001). Therefore, in the current study the three antigens were injected concurrently and in different locations on the mice. The result was antibody responses to the three antigens that were not diminished, yet did not result in elevated levels of protective immunity.

As an alternative approach, fusion proteins consisting of two or three of the protective recombinant antigens were tested for their efficacy in the vaccine against infection with $O$. volvulus. Mice immunized with $O v$-RAL-2/103, $O v$-RAL-2/CPI-2M or $O v$-103/RAL-2/ CPI-2M fusion proteins had significant levels of larval killing and host protection. Mice immunized with the two or three-antigen fusion proteins had endpoint titers to the single antigens that were at least comparable with the titers seen in mice immunized with individual antigens. Antibody endpoint titers for the fusion proteins were significantly higher than the antibody responses in these mice to the individual antigens of which the fusions were composed. Even in the face of the significantly enhanced antibody titers the levels of protective immunity were not enhanced in the mice immunized with the double or triple fusion proteins. Fusion protein vaccines developed against Plasmodium falciparum have better efficacy than antigen cocktails (Faber et al., 2007, 2013; Alaro et al., 2013). A multivalent fusion protein vaccine against $B$. malayi conferred $95 \%$ protection in mice (Dakshinamoorthy et al., 2013). Interestingly, it was concluded in a recent review that mice have a high degree of natural resistance to infection with B. malayi and that almost every reported vaccine trial using a wide range of vaccine components has demonstrated efficacy in mice against infection with B. malayi (Morris et al., 2013). Mice are resistant to infection with both $B$. malayi and $O$. volvulus, yet high levels of protective immunity can be induced against $B$. malayi, whereas only moderate levels of immunity can be induced against $O$. volvulus in mice regardless of the immunization regimen. A possible explanation is that $O$. 
volvulus may have developed immune evasion mechanisms, differing from those developed by $B$. malayi, that the mouse immune response cannot supersede.

In summary, out of eight vaccine candidates tested in this study, $O v-103, O v$-RAL-2 and $O v$ CPI-2M - individually, as fusion proteins and in combination - were shown to reproducibly induce protective immunity in mice. The levels of protective immunity that were induced by these antigens were moderate and may reflect a limitation of the ability of the immune response ability to kill parasites within diffusion chambers. Jirds immunized against Acanthocheilonema viteae displayed low levels of parasite killing within diffusion chambers while simultaneously killing parasites within the tissues (Taylor et al., 1995). Alternatively, the limited time of exposure that the immune response had to the parasites may have retarded the ability of the immune response to kill the worms. Evidence from immunization trials against Dirofilaria immitis in dogs have shown that the protective immune response killed approximately $50 \%$ of the parasites contained within diffusion chambers at 3 weeks post-challenge and $98 \%$ of the parasites at 6 months post-challenge (Grieve et al., 1988). In parallel experiments to those described in this study, Mongolian gerbils were vaccinated with homologous B. malayi antigens produced in the same protein expression systems and administered using the same adjuvants and vaccine schedules described herein. Significant reductions in adult worm recovery were seen in gerbils vaccinated with $\mathrm{Bm}$-103, Bm-RAL-2 and $B m$-CPI-2M (T. Klei, unpublished data). We therefore posit that the levels of protective immunity observed in the current study, induced by the three protective antigens, do not reflect the true potential of these vaccines to induce protective immunity in the clinical setting. Although the present data do not take into account repeated exposures which occur in the field during ongoing transmission, we still submit that a vaccine composed of these three antigens will function in humans at levels greatly exceeding those seen in mice and will protect the vaccinated individuals from infection and disease caused by $O$. volvulus.

\section{Acknowledgments}

This work was support by National Institutes of Health/National Institute of Allergy and Infectious Diseases, USA grant number 1R01AI078314.

\section{References}

Abraham D, Leon O, Leon S, Lustigman S. Development of a recombinant antigen vaccine against infection with the filarial worm Onchocerca volvulus. Infect Immun. 2001; 69:262-270. [PubMed: 11119514]

Abraham D, Leon O, Schnyder-Candrian S, Wang CC, Galioto AM, Kerepesi LA, Lee JJ, Lustigman S. Immunoglobulin E and eosinophil-dependent protective immunity to larval Onchocerca volvulus in mice immunized with irradiated larvae. Infect Immun. 2004; 72:810-817. [PubMed: 14742524]

Abraham D, Lucius R, Trees AJ. Immunity to Onchocerca spp. in animal hosts. Trends Parasitol. 2002; 18:164-171. [PubMed: 11998704]

Alaro JR, Partridge A, Miura K, Diouf A, Lopez AM, Angov E, Long CA, Burns JM Jr. A chimeric Plasmodium falciparum merozoite surface protein vaccine induces high titers of parasite growth inhibitory antibodies. Infect Immun. 2013; 81:3843-3854. [PubMed: 23897613]

Anand SB, Kodumudi KN, Reddy MV, Kaliraj P. A combination of two Brugia malayi filarial vaccine candidate antigens (BmALT-2 and BmVAH) enhances immune responses and protection in jirds. $\mathbf{J}$ Helminthol. 2011; 85:442-452. [PubMed: 21208482] 
Ardelli BF, Guerriero SB, Prichard RK. Genomic organization and effects of ivermectin selection on Onchocerca volvulus P-glycoprotein. Mol Biochem Parasitol. 2005; 143:58-66. [PubMed: 15993957]

Asojo OA, Loukas A, Inan M, Barent R, Huang J, Plantz B, Swanson A, Gouthro M, Meagher MM, Hotez PJ. Crystallization and preliminary X-ray analysis of Na-ASP-1, a multi-domain pathogenesis-related-1 protein from the human hookworm parasite Necator americanus. Acta crystallogr. 2005; F 61:391-394.

Awadzi K, Attah SK, Addy ET, Opoku NO, Quartey BT, Lazdins-Helds JK, Ahmed K, Boatin BA, Boakye DA, Edwards G. Thirty-month follow-up of sub-optimal responders to multiple treatments with ivermectin, in two onchocerciasis-endemic foci in Ghana. Ann Trop Med Parasitol. 2004a; 98:359-370. [PubMed: 15228717]

Awadzi K, Boakye DA, Edwards G, Opoku NO, Attah SK, Osei-Atweneboana MY, Lazdins-Helds JK, Ardrey AE, Addy ET, Quartey BT, Ahmed K, Boatin BA, Soumbey-Alley EW. An investigation of persistent microfilaridermias despite multiple treatments with ivermectin, in two onchocerciasis-endemic foci in Ghana. Ann Trop Med Parasitol. 2004b; 98:231-249. [PubMed: 15119969]

Babayan SA, Luo H, Gray N, Taylor DW, Allen JE. Deletion of parasite immune modulatory sequences combined with immune activating signals enhances vaccine mediated protection against filarial nematodes. PLoS Neglected Trop Dis. 2012; 6:e1968.

Boatin BA, Richards FO Jr. Control of onchocerciasis. Adv Parasitol. 2006; 61:349-394. [PubMed: 16735169]

Bonne-Annee S, Kerepesi LA, Hess JA, O'Connell AE, Lok JB, Nolan TJ, Abraham D. Human and mouse macrophages collaborate with neutrophils to kill larval Strongyloides stercoralis. Infect Immun. 2013; 81:3346-3355. [PubMed: 23798541]

Bourguinat C, Pion SD, Kamgno J, Gardon J, Gardon-Wendel N, Duke BO, Prichard RK, Boussinesq M. Genetic polymorphism of the beta-tubulin gene of Onchocerca volvulus in ivermectin naive patients from Cameroon, and its relationship with fertility of the worms. Parasitology. 2005:1-8.

Bourguinat C, Pion SDS, Kamgno J, Gardon J, Duke BOL, Boussinesq M, Prichard RK. Genetic selection of low fertile Onchocerca volvulus by ivermectin treatment. PLoS Negl Trop Dis. 2007; 1:e72. [PubMed: 17989786]

Brewer JM, Conacher M, Satoskar A, Bluethmann H, Alexander J. In interleukin-4-deficient mice, alum not only generates T helper 1 responses equivalent to freund's complete adjuvant, but continues to induce T helper 2 cytokine production. Eur J Immunol. 1996; 26:2062-2066. [PubMed: 8814247]

Christoffersson G, Vagesjo E, Vandooren J, Liden M, Massena S, Reinert RB, Brissova M, Powers AC, Opdenakker G, Phillipson M. VEGF-A recruits a proangiogenic MMP-9-delivering neutrophil subset that induces angiogenesis in transplanted hypoxic tissue. Blood. 2012; 120:4653-4662. [PubMed: 22966168]

Dakshinamoorthy G, Samykutty AK, Munirathinam G, Reddy MV, Kalyanasundaram R. Multivalent fusion protein vaccine for lymphatic filariasis. Vaccine. 2013; 31:1616-1622. [PubMed: 23036503]

Diawara L, Traore MO, Badji A, Bissan Y, Doumbia K, Goita SF, Konate L, Mounkoro K, Sarr MD, Seck AF, Toe L, Touree S, Remme JH. Feasibility of onchocerciasis elimination with ivermectin treatment in endemic foci in Africa: first evidence from studies in Mali and Senegal. PLoS Neglected Trop Dis. 2009; 3:e497.

Duke BOL, Moore PJ. The contributions of different age groups to the transmission of onchocerciasis in a Cameroon forest village. Trans R Soc Trop Med Hyg. 1968; 62:22-28. [PubMed: 5639533]

Eng JK, Prichard RK. A comparison of genetic polymorphism in populations of Onchocerca volvulus from untreated- and ivermectin-treated patients. Mol Biochem Parasitol. 2005; 142:193-202. [PubMed: 15885823]

Faber BW, Remarque EJ, Morgan WD, Kocken CH, Holder AA, Thomas AW. Malaria vaccinerelated benefits of a single protein comprising Plasmodium falciparum apical membrane antigen 1 domains I and II fused to a modified form of the 19-kilodalton C-terminal fragment of merozoite surface protein 1. Infect Immun. 2007; 75:5947-5955. [PubMed: 17938224] 
Faber BW, Younis S, Remarque EJ, Rodriguez Garcia R, Riasat V, Walraven V, van der Werff N, van der Eijk M, Cavanagh DR, Holder AA, Thomas AW, Kocken CH. Diversity covering AMA1MSP119 fusion proteins as malaria vaccines. Infect Immun. 2013; 81:1479-1490. [PubMed: 23429538]

Gardon J, Gardon-Wendel N, Demanga N, Kamgno J, Chippaux JP, Boussinesq M. Serious reactions after mass treatment of onchocerciasis with ivermectin in an area endemic for Loa loa infection. Lancet. 1997; 350:18-22. [PubMed: 9217715]

Giersing B, Miura K, Shimp R, Wang J, Zhou H, Orcutt A, Stowers A, Saul A, Miller LH, Long C, Singh S. posttranslational modification of recombinant Plasmodium falciparum apical membrane antigen 1: impact on functional immune responses to a malaria vaccine candidate. Infect Immun. 2005; 73:3963-3970. [PubMed: 15972483]

Goud GN, Zhan B, Ghosh K, Loukas A, Hawdon J, Dobardzic A, Deumic V, Liu S, Dobardzic R, Zook BC, Jin Q, Liu Y, Hoffman L, Chung-Debose S, Patel R, Mendez S, Hotez PJ. Cloning, yeast expression, isolation, and vaccine testing of recombinant Ancylostoma-secreted protein (ASP)-1 and ASP-2 from Ancylostoma ceylanicum. J Infect Dis. 2004; 189:919-929. [PubMed: 14976610]

Gregory WF, Maizels RM. Cystatins from filarial parasites: evolution, adaptation and function in the host-parasite relationship. Int J Biochem Cell Biol. 2008; 40:1389-1398. [PubMed: 18249028]

Grieve RB, Abraham D, Mika-Grieve M, Seibert BP. Induction of protective immunity in dogs to infection with Dirofilaria immitis using chemically-abbreviated infections. Am J Trop Med Hyg. 1988; 39:373-379. [PubMed: 3189698]

Hohenblum H, Gasser B, Maurer M, Borth N, Mattanovich D. Effects of gene dosage, promoters, and substrates on unfolded protein stress of recombinant Pichia pastoris. Biotechnol Bioeng. 2004; 85:367-375. [PubMed: 14755554]

Huang YJ, Prichard RK. Identification and stage-specific expression of two putative P-glycoprotein coding genes in Onchocerca volvulus. Mol Biochem Parasitol. 1999; 102:273-281. [PubMed: 10498183]

Joseph SK, Ramaswamy K. Single multivalent vaccination boosted by trickle larval infection confers protection against experimental lymphatic filariasis. Vaccine. 2013; 31:3320-3326. [PubMed: 23735679]

Kastenmuller K, Espinosa DA, Trager L, Stoyanov C, Salazar AM, Pokalwar S, Singh S, Dutta S, Ockenhouse CF, Zavala F, Seder RA. Full-length Plasmodium falciparum circumsporozoite protein administered with long-chain poly(I.C) or the Toll-like receptor 4 agonist glucopyranosyl lipid adjuvant-stable emulsion elicits potent antibody and CD4+ T cell immunity and protection in mice. Infect Immun. 2013; 81:789-800. [PubMed: 23275094]

Kenney JS, Hughes BW, Masada MP, Allison AC. Influence of adjuvants on the quantity, affinity, isotype and epitope specificity of murine antibodies. J Immunol Meth. 1989; 121:157-166.

Kohler P. The biochemical basis of anthelmintic action and resistance. Int J Parasitol. 2001; 31:336345. [PubMed: 11400692]

Lange AM, Yutanawiboonchai W, Lok JB, Trpis M, Abraham D. Induction of protective immunity against larval Onchocerca volvulus in a mouse model. Am J Trop Med Hyg. 1993; 49:783-788. [PubMed: 8279644]

Lange AM, Yutanawiboonchai W, Scott P, Abraham D. IL-4- and IL-5-dependent protective immunity to Onchocerca volvulus infective larvae in BALB/cBYJ mice. J Immunol. 1994; 153:205-211. [PubMed: 8207236]

Lee JJ, Jacobsen EA, McGarry MP, Schleimer RP, Lee NA. Eosinophils in health and disease: the LIAR hypothesis Clinical and experimental allergy. J Brit Soc Allergy Clin Immunol. 2010; 40:563-575.

Lustigman S, James ER, Tawe W, Abraham D. Towards a recombinant antigen vaccine against Onchocerca volvulus. Trends Parasitol. 2002; 18:135-141. [PubMed: 11854092]

Lustigman S, MacDonald AJ, Abraham D. CD4+ dependent immunity to Onchocerca volvulus thirdstage larvae in humans and the mouse vaccination model: common ground and distinctions. Int $\mathrm{J}$ Parasitol. 2003; 33:1161-1171. [PubMed: 13678632] 
MacDonald AJ, Tawe W, Leon O, Cao L, Liu J, Oksov Y, Abraham D, Lustigman S. Ov-ASP-1, the Onchocerca volvulus homologue of the activation associated secreted protein family is immunostimulatory and can induce protective anti-larval immunity. Parasite Immunol. 2004; 26:53-62. [PubMed: 15198646]

MacDonald AJ, Turaga PS, Harmon-Brown C, Tierney TJ, Bennett KE, McCarthy MC, Simonek SC, Enyong PA, Moukatte DW, Lustigman S. Differential cytokine and antibody responses to adult and larval stages of Onchocerca volvulus consistent with the development of concomitant immunity. Infect Immun. 2002; 70:2796-2804. [PubMed: 12010965]

Makepeace BL, Jensen SA, Laney SJ, Nfon CK, Njongmeta LM, Tanya VN, Williams SA, Bianco AE, Trees AJ. Immunisation with a multivalent, subunit vaccine reduces patent infection in a natural bovine model of onchocerciasis during intense field exposure. PLoS Neglected Trop Dis. 2009; 3:e544.

McCarthy JS, Wieseman M, Tropea J, Kaslow D, Abraham D, Lustigman S, Tuan R, Guderian RH, Nutman TB. Onchocerca volvulus glycolytic enzyme fructose-1,6-bisphosphate aldolase as a target for a protective immune response in humans. Infect Immun. 2002; 70:851-858. [PubMed: 11796620]

Morris CP, Evans H, Larsen SE, Mitre E. A comprehensive, model-based review of vaccine and repeat infection trials for filariasis. Clin Microbiol Rev. 2013; 26:381-421. [PubMed: 23824365]

Njongmeta LM, Nfon CK, Gilbert J, Makepeace BL, Tanya VN, Trees AJ. Cattle protected from onchocerciasis by ivermectin are highly susceptible to infection after drug withdrawal. Int $\mathrm{J}$ Parasitol. 2004; 34:1069-1074. [PubMed: 15313133]

Osei-Atweneboana MY, Eng JK, Boakye DA, Gyapong JO, Prichard RK. Prevalence and intensity of Onchocerca volvulus infection and efficacy of ivermectin in endemic communities in Ghana: a two-phase epidemiological study. Lancet. 2007; 369:2021-2029. [PubMed: 17574093]

Shrivastava N, Singh PK, Nag JK, Kushwaha S, Misra-Bhattacharya S. Immunization with a multisubunit vaccine considerably reduces establishment of infective larvae in a rodent model of Brugia malayi. Comp Immunol Microbiol Infect Dis. 2013; 36:507-519. [PubMed: 23829972]

Taylor MJ, van Es RP, Shay K, Townson S, Bianco AE. Acanthocheilonema viteae: reduction in the expression of protective immunity against infective larvae in the jird as assessed by micropore chamber vs systemic challenge infections. Exp Parasitol. 1995; 80:560-562. [PubMed: 7729490]

Tchakoute VL, Graham SP, Jensen SA, Makepeace BL, Nfon CK, Njongmeta LM, Lustigman S, Enyong PA, Tanya VN, Bianco AE, Trees AJ. In a bovine model of onchocerciasis, protective immunity exists naturally, is absent in drug-cured hosts, and is induced by vaccination. Proc Nat Acad Sci USA. 2006; 103:5971-5976. [PubMed: 16585501]

Trpis M, Scoles GA, Struble RH. Cryopreservation of infective larvae of Onchocerca volvulus (Filarioidea: Onchocercidae). J Parasitol. 1993; 79:695-700. [PubMed: 8410541]

Tsuda Y, Takahashi H, Kobayashi M, Hanafusa T, Herndon DN, Suzuki F. Three different neutrophil subsets exhibited in mice with different susceptibilities to infection by methicillin- resistant Staphylococcus aureus. Immunity. 2004; 21:215-226. [PubMed: 15308102]

Winnen M, Plaisier AP, Alley ES, Nagelkerke NJ, van Oortmarssen G, Boatin BA, Habbema JD. Can ivermectin mass treatments eliminate onchocerciasis in Africa? Bull World Health Organ. 2002; 80:384-391. [PubMed: 12077614]

Yang YL, Chang SH, Gong X, Wu J, Liu B. Expression, purification and characterization of lowglycosylation influenza neuraminidase in alpha-1,6-mannosyltransferase defective Pichia pastoris. Mol Biol Reports. 2012; 39:857-864.

Yip HC, Karulin AY, Tary-Lehmann M, Hesse MD, Radeke H, Heeger PS, Trezza RP, Heinzel FP, Forsthuber T, Lehmann PV. Adjuvant-guided type-1 and type-2 immunity: infectious/ noninfectious dichotomy defines the class of response. J Immunol. 1999; 162:3942-3949. [PubMed: 10201913]

Zhan B, Hotez PJ, Wang Y, Hawdon JM. A developmentally regulated metalloprotease secreted by host-stimulated Ancylostoma caninum third-stage infective larvae is a member of the astacin family of proteases. Mol Biochem Parasitol. 2002; 120:291-296. [PubMed: 11897134] 
Zhang DM, Pan WQ, Qian L, Duke M, Shen LH, McManus DP. Investigation of recombinant Schistosoma japonicum paramyosin fragments for immunogenicity and vaccine efficacy in mice. Parasite Immunol. 2006; 28:77-84. [PubMed: 16441505] 
A vaccine against onchocerciasis is essential for the control of this disease

Three antigens were shown to induce protective immunity against Onchocerca volvulus

Multivalent vaccine did not increase protective immunity

Antigens remain candidates for inclusion in onchocerciasis vaccine for humans 


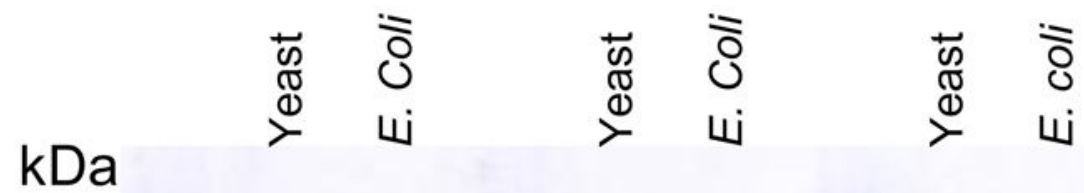

KDa

98

64

50

36

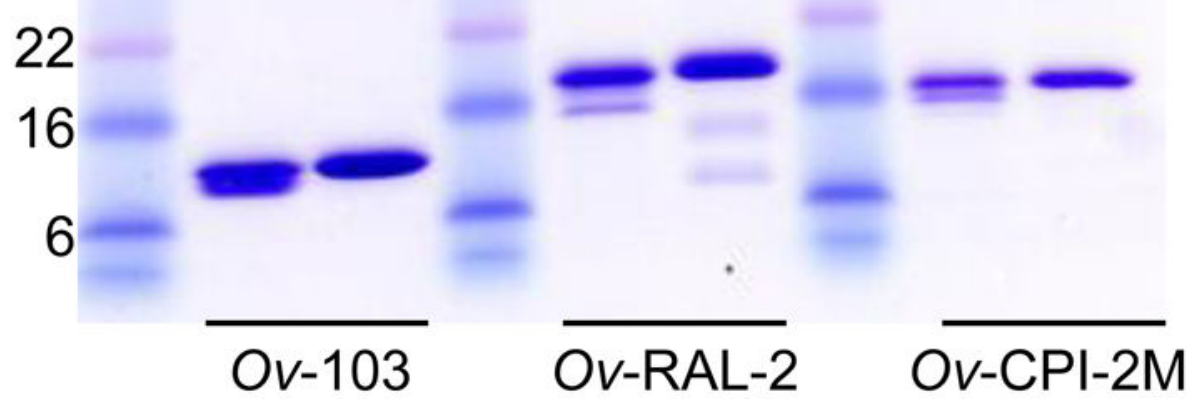

Fig. 1.

SDS-PAGE and Coomassie staining of purified recombinant Onchocerca volvulus $O v-103$, $O v$-RAL-2 and $O v$-CPI-2M proteins expressed in Pichia pastoris (yeast) and Escherichia coli. SeeBlue pre-stained proteins (Invitrogen) were used as standard markers. A total of 1 $\mu \mathrm{g}$ was loaded for each recombinant protein. 

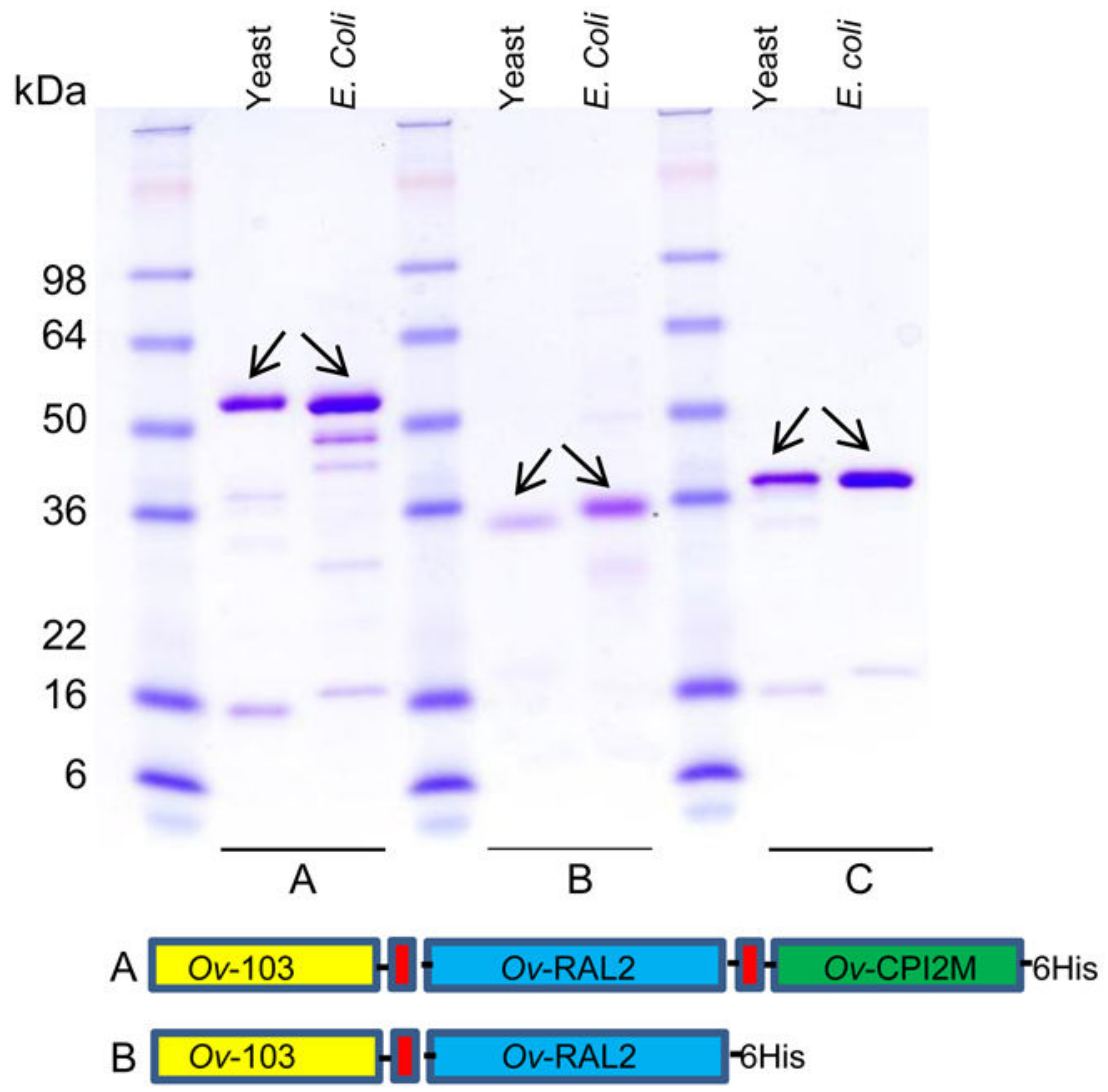

C

Ov-RAL2 $-\mathrm{Ov}-\mathrm{CPI} 2 \mathrm{M}-\mathrm{His}$

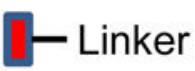

Fig. 2.

SDS-PAGE of purified recombinant fusion proteins and their construct diagrams $(\mathrm{A}-\mathrm{C})$. The fusion proteins of three or two protective Onchocerca volvulus $(O v)$ filarial antigen combinations were constructed as shown in the diagram. The recombinant fusion proteins were expressed in Pichia pastoris (yeast) and Escherichia coli and loaded on SDS-PAGE (each $1 \mu \mathrm{g}$, indicated with arrows). SeeBlue pre-stained proteins (Invitrogen) were used as standard markers. 6His, 6-hexahisitidine tag. 
$3 \mathrm{~A}$

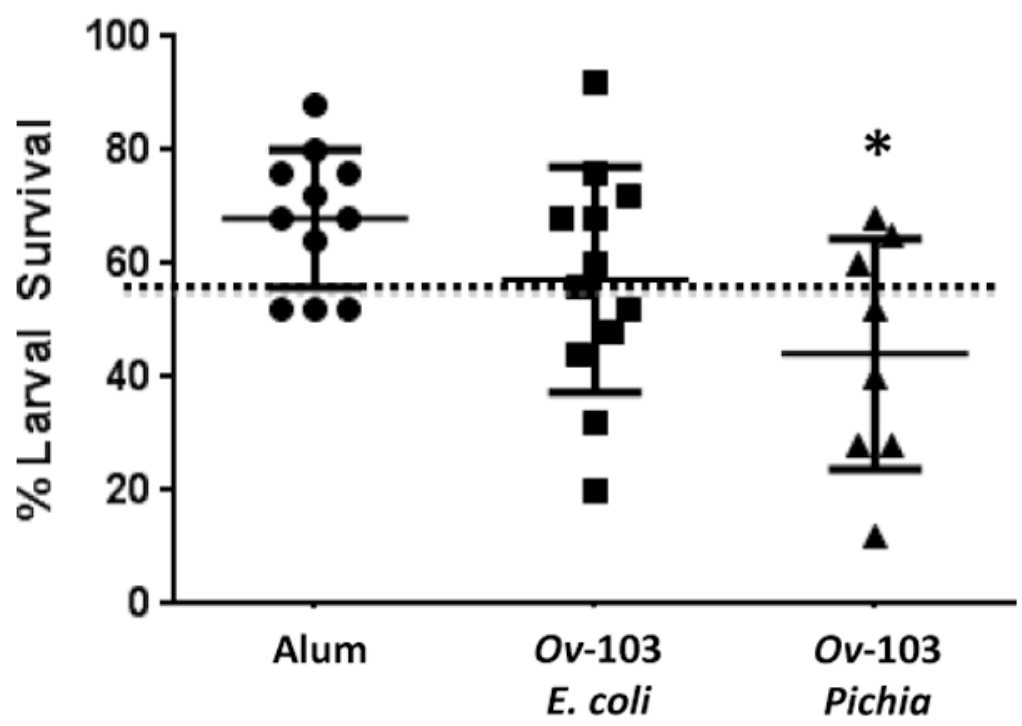

3B

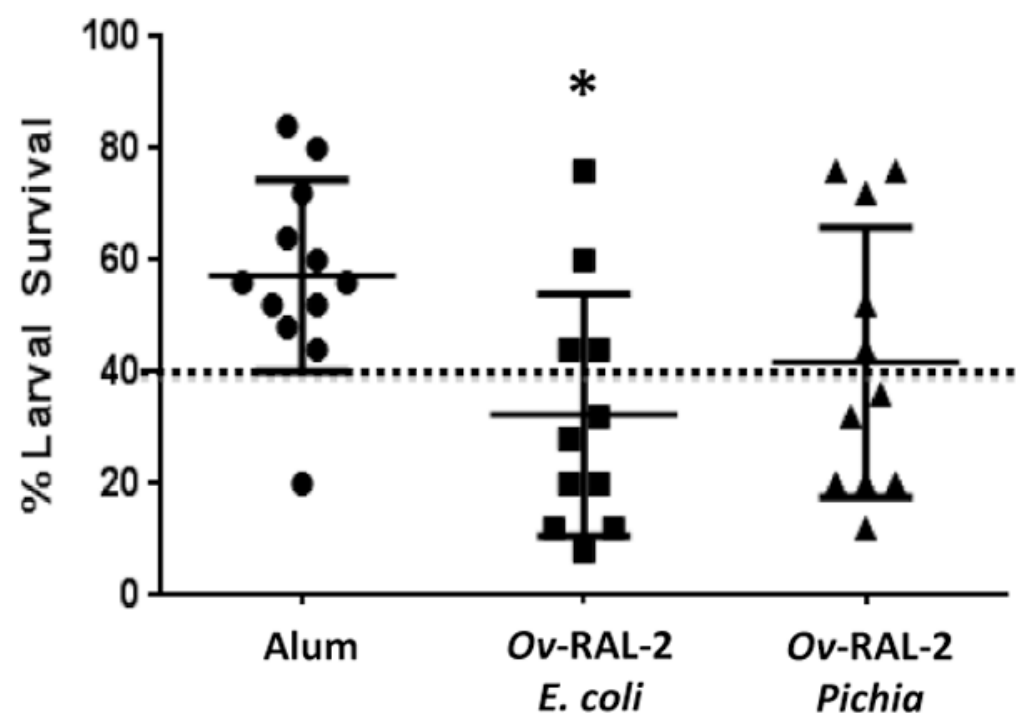




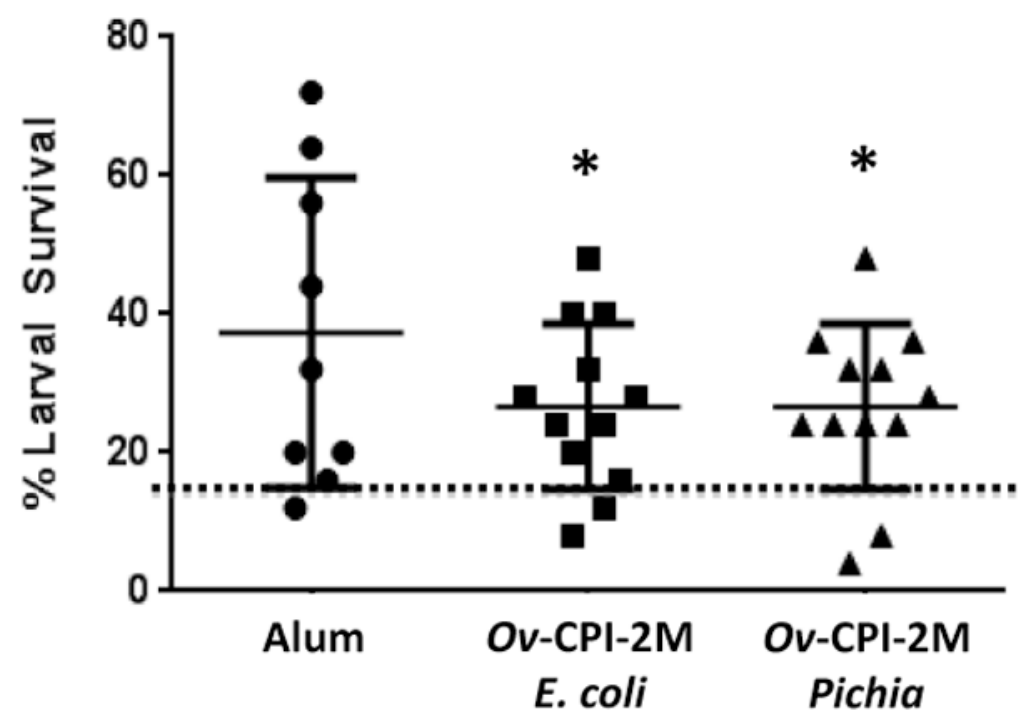

Fig. 3.

Effect of immunization with a single vaccine antigen expressed by either Escherichia coli or Pichia pastoris on the development of protective immunity to Onchocerca volvulus larvae in mice. (A) $O v$-103; (B) $O v$-RAL-2; (C) $O v$-CPI-2M. Each dot represents larval recovery from an individual animal. Data presented are mean \pm S.D. Asterisk represents statistical difference in larval recoveries; $P \leq 0.05$. 


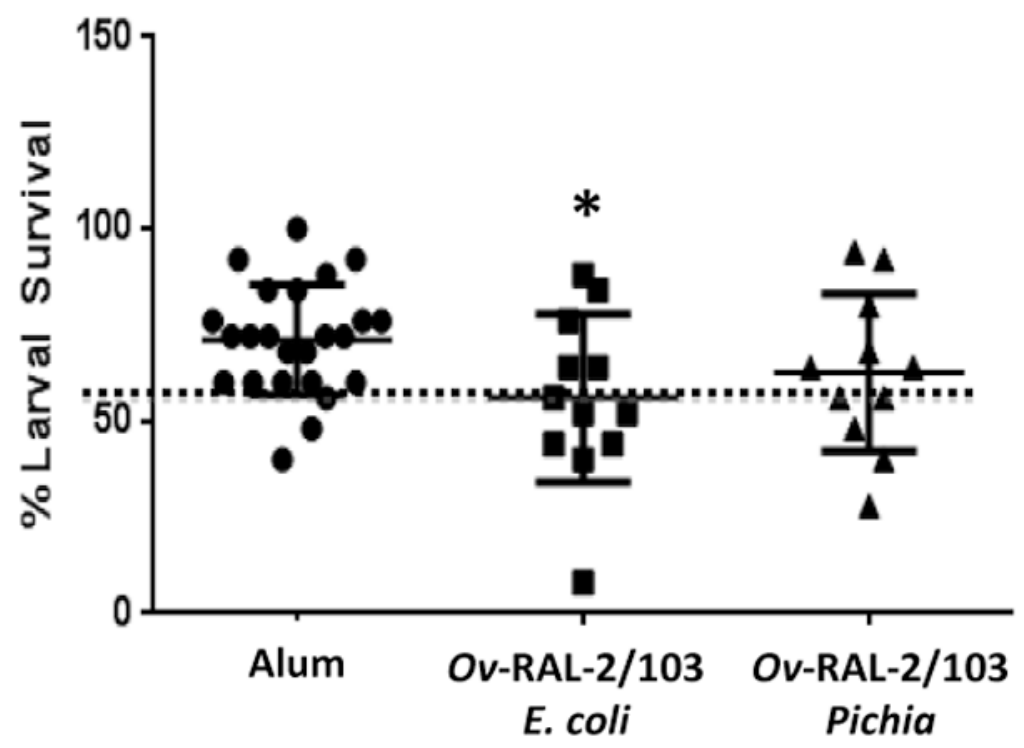

4B

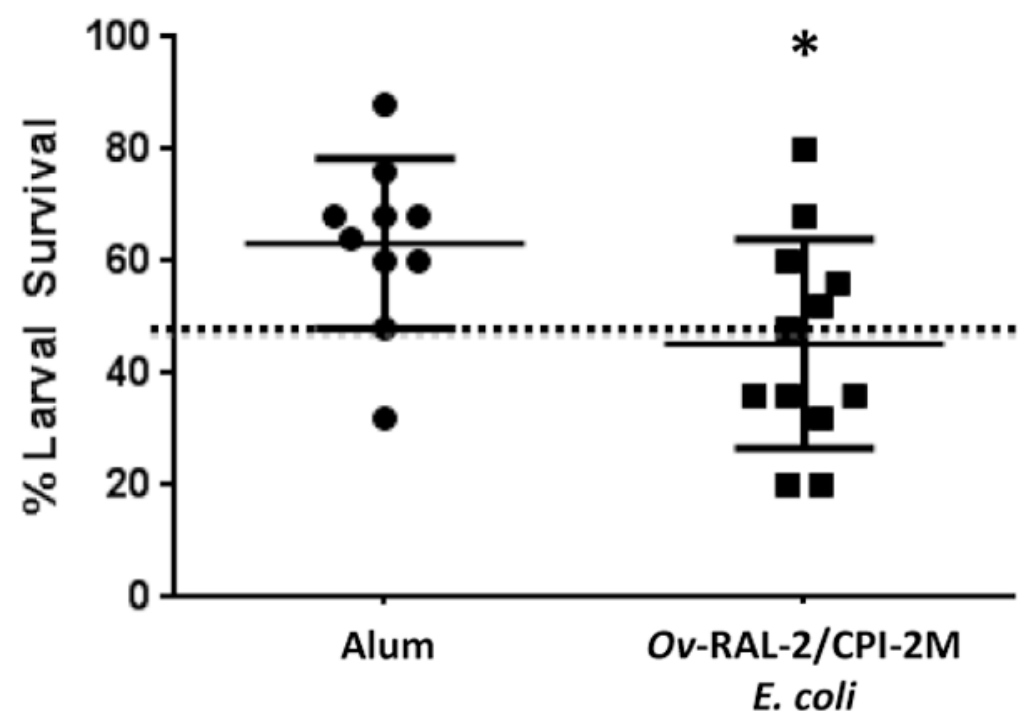

Fig. 4.

Effect of immunization with fusion antigens on the development of protective immunity to Onchocerca volvulus larvae in mice. (A) $O v$-RAL-2/103 fusion protein expressed in Escherichia coli and Pichia pastoris expressed protein. (B) $O v$-RAL-2/CPI-2M expressed in E. coli. Each dot represents larval recovery from an individual animal. Data presented are mean \pm S.D. Asterisk represents statistical difference in larval recoveries; $P \leq 0.05$. 


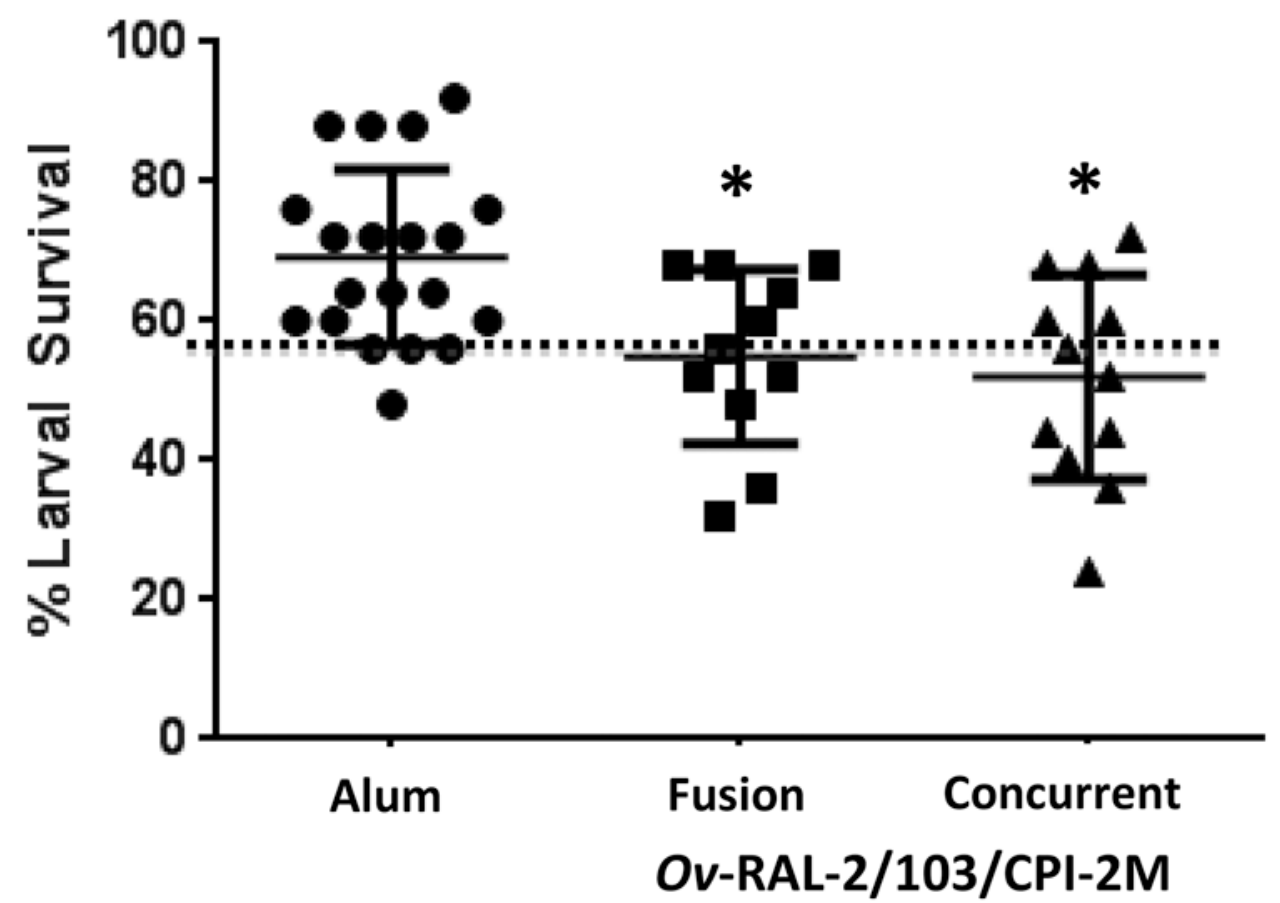

Fig. 5.

Comparative effect of immunization with concurrent injections of Onchocerca volvulus $O v$-103 (expressed in Pichia pastoris), Ov-RAL-2 (expressed in Escherichia coli) and $O v$ CPI-2M (expressed in $E$. coli) compared with immunization with the combined fusion antigen $O v$-RAL-2/103/CPI-2M (expressed in E. coli). Each dot represents larval recovery from an individual animal. Data presented are mean \pm S.D. Asterisk represents statistical difference in larval recoveries; $P \leq 0.05$. 


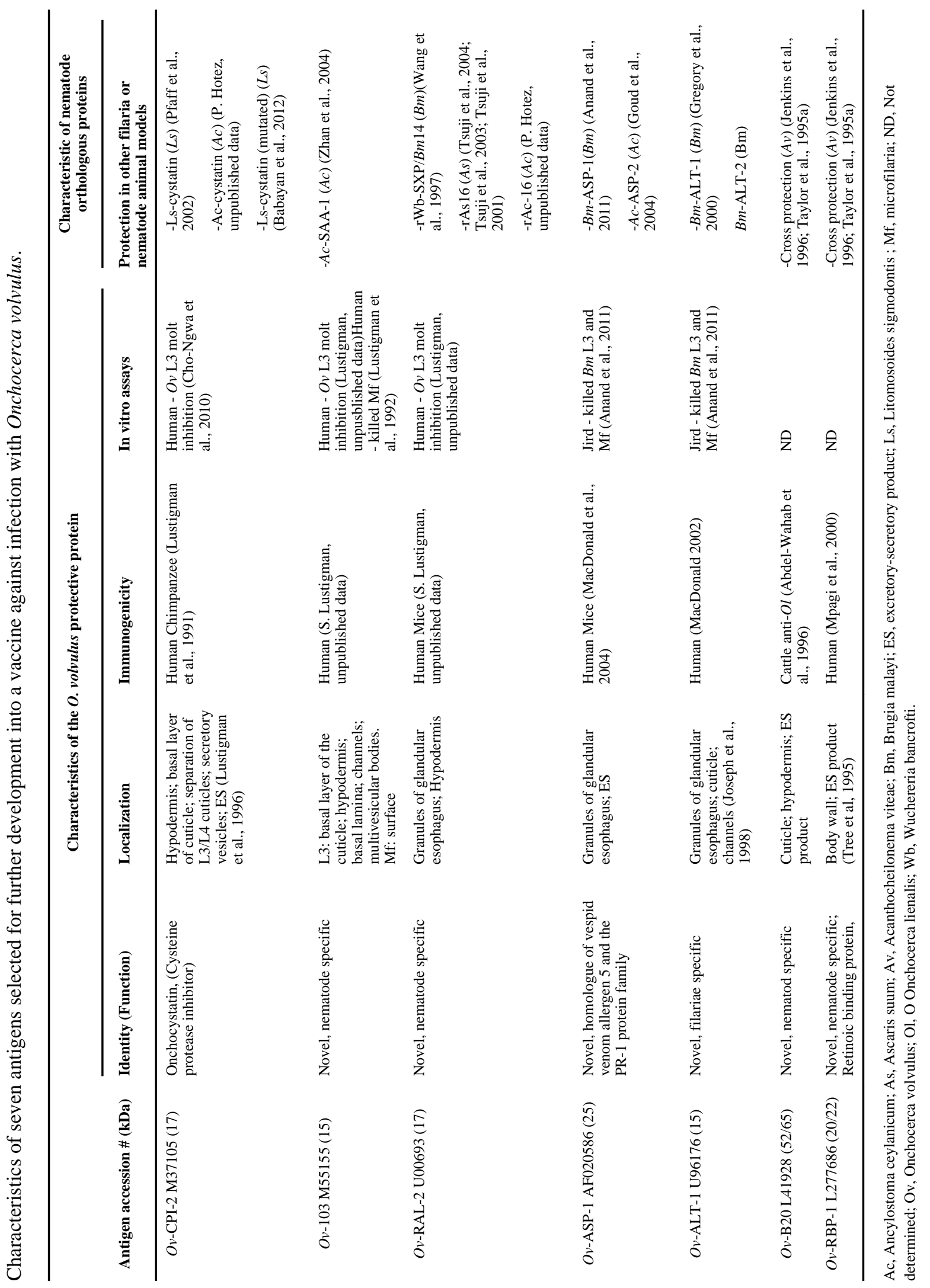




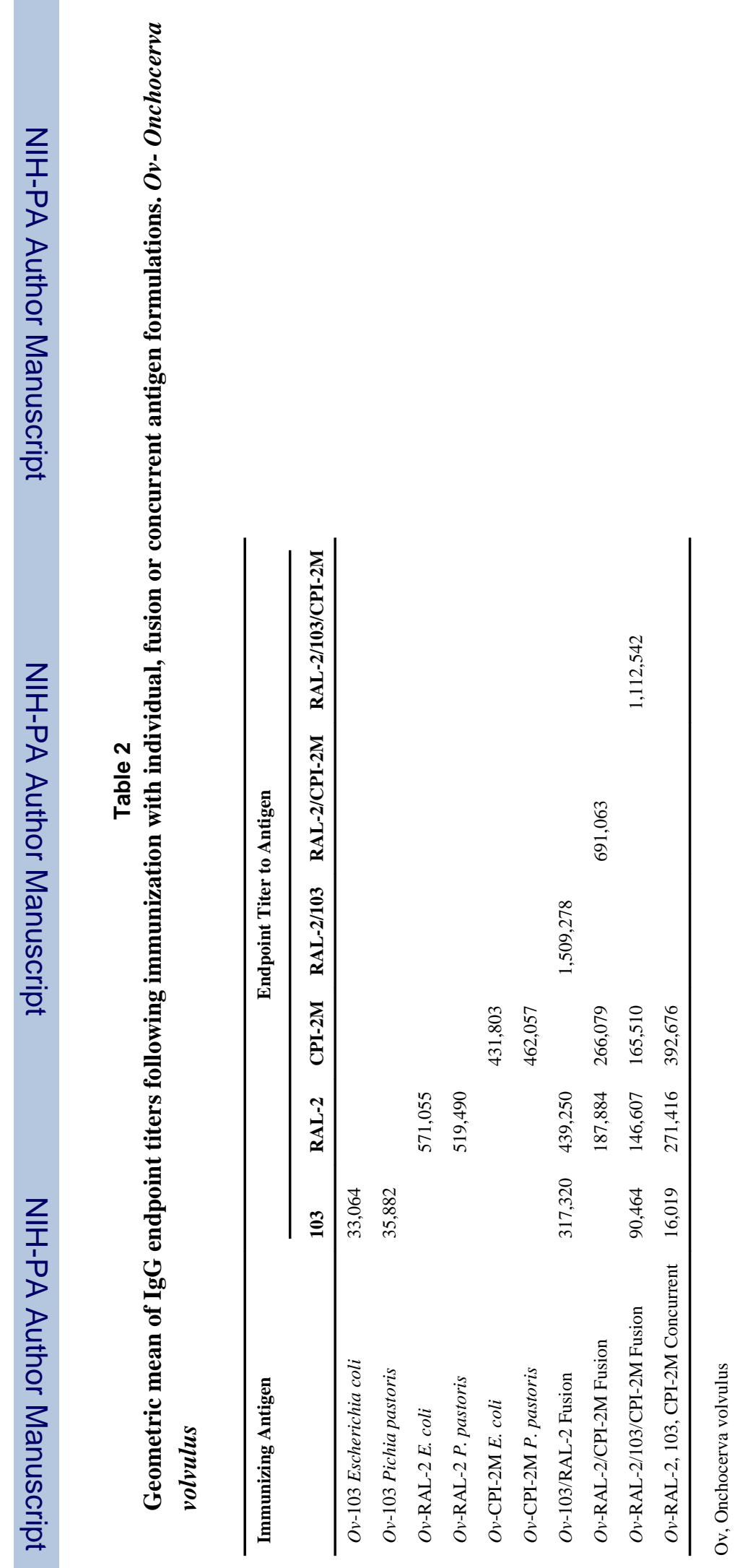

Int J Parasitol. Author manuscript; available in PMC 2015 August 01. 